\title{
The association between antidepressant medications and coronary heart disease in Brazil: a cross-sectional analysis on the Brazilian longitudinal study of adult health (ELSA-Brazil)
}

\section{Andrew H. Kemp ${ }^{1,2}{ }^{*}$, Andre R. Brunoni ${ }^{1}$, Marcio S. Bittencourt ${ }^{1}$, Maria A. Nunes ${ }^{3}$, Isabela M. Benseñor ${ }^{1}$ and Paulo A. Lotufo ${ }^{1}$}

${ }^{1}$ Faculty of Medicine, University Hospital, University of São Paulo, São Paulo, Brazil

2 School of Psychology and Discipline of Psychiatry, University of Sydney, Sydney, NSW, Australia

${ }^{3}$ Faculty of Medicine, Federal University of Rio Grande do Sul, Porto Alegre, Brazil

\section{Edited by:}

Yuanzhang Li, Walter Reed Army Institute of Research, USA

\section{Reviewed by:}

Arthur Eumann Mesas, Universidade

Estadual de Londrina, Brazil

Wenlong Gao, Lanzhou University,

China

\section{${ }^{*}$ Correspondence:}

Andrew H. Kemp, Center for Clinical and Epidemiologic Research, University Hospital, University of São Paulo, Av. Prof. Lineu Prestes 2565, São Paulo CEP 05508-000, Brazil e-mail: andrew.kemp@hu.usp.br; andrew.kemp@sydney.edu.au
Background: Recent studies have highlighted associations between use of antidepressant medications and coronary heart disease (CHD). Tricyclic antidepressants (TCA) are not recommended in patients with $\mathrm{CHD}$ as they may increase morbidity and mortality. However, this class of antidepressants is freely prescribed in public health pharmacies, while access to other classes of antidepressants is restricted in Brazil. Here, we examine the associations between antidepressant use and prevalent CHD in a large cohort from Brazil.

Methods: Participants included 14,994 civil servants aged 35-74 years from the baseline assessment of the Brazilian Longitudinal Study of Adult Health (ELSA-Brasil). CHD ( $n=710)$ included stable angina, myocardial infarction, and coronary revascularization. Univariate (unadjusted) and multivariate (adjusted) logistic regression analyses were conducted to estimate odds ratios and confidence intervals.

Results: After full adjustment for covariates, TCA use $(n=156)$ was associated with a twofold increase in prevalent CHD, relative to non-use $(n=14,076)$. Additional sensitivity analysis revealed a threefold association for myocardial infarction (OR: $2.96,95 \% \mathrm{Cl}$ : 1.41-6.21) and coronary revascularization (OR: 2.92, 95\% Cl: 1.28-6.66). There were no significant associations between antidepressant use and stable angina pectoris.

Conclusion: Findings highlight a strong association between TCA use and prevalent CHD. While the cross-sectional design is an important limitation of the present study, findings have important implications for the treatment of cardiac patients in Brazil.

Keywords: tricyclic antidepressants, coronary heart disease, Brazil, cross-sectional design, clinical epidemiology, TCA, CHD

\section{INTRODUCTION}

Coronary heart disease (CHD) and major depressive disorder (MDD) are leading burdens of disease (1) and the relationship between these disorders is bidirectional: patients with CHD have more MDD than the general population, while those with MDD are more likely to develop CHD $(2,3)$. Critically, comorbidity between CHD and MDD increases risk of further morbidity and mortality (4). Other studies have highlighted the association between CHD and the anxiety disorders $(5,6)$. Antidepressant use in patients with $\mathrm{CHD}$ is controversial. While use of tricyclic antidepressants (TCA) is not recommended (7), research indicates that all classes of antidepressant medications may have adverse cardiac effects $(8,9)$ [but see Ref. $(10,11)$ in regards to the selective serotonin reuptake inhibitor, or SSRI, antidepressant class]. The selective serotonin reuptake inhibitors are generally considered to be the safest class of antidepressants for use in cardiac patients (12) when needed. Here, we examine the association between antidepressant use and prevalent CHD in a large epidemiological cohort from Brazil.

The cardiovascular risks of TCA are well known (13). Although initially it was believed that TCAs could suppress arrhythmias in depressed patients with pre-existing arrhythmias, this belief was revised more than 20 years ago (13). The TCAs are also potent antagonists of muscarinic acetylcholine receptors (14) at the sinoatrial node of the heart leading to a decrease in parasympathetic activity, disinhibition of sympathetic nervous system activity, and tachycardia (15), which may lead to adverse cardiovascular events. While an earlier case-control study (16) reported that TCAs only increased the risk of myocardial infarction within the initial 28 days of antidepressant use, more recent research (17) demonstrated that use of TCAs are associated with a $35 \%$ increased risk of cardiovascular death over an 8-year follow-up period in initially healthy individuals. Consistent with this body of literature, a recent consensus statement from the National Heart Foundation 
of Australia (7), a high-income country, recommends that TCA be avoided in patients with CHD and depression.

While recommendations are helpful, they are difficult to apply in less-developed countries. Brazil is an upper-middle-income country facing major social challenges that may impact on the associations between $\mathrm{CHD}$ and antidepressant use. We have reported previously (18) that only 14 and $16.5 \%$ of patients in Brazil with generalized anxiety and MDD, respectively, take antidepressant medication. We also observed that while SSRIs were prescribed twice more frequently than tricyclic medications, antidepressant use was related to having private health insurance. TCA are freely dispensed in public health pharmacies in Brazil, while most of the SSRI medications are not, with the exception of fluoxetine and, in some regions of Brazil including São Paulo, sertraline $(18,19)$. (The list of medicines supplied by the Brazilian Unified Health System, or SUS, in São Paulo is available here: http://www2. hu.usp.br/confira-lista-de-medicamentos-do-sus/.) TCA therefore play an important role in treating depression, as well as a variety of other conditions including neuropathic pain and fibromyalgia (20) in Brazil. This context provides an important background for the current study, which sought to determine the associations between use of antidepressant medications and prevalent CHD in the Brazilian Longitudinal Study of Adult Health (ELSA-Brasil) $(21,22)$ cohort. We examine associations in the cohort at baseline to provide an important foundation for future prospective analyses on this cohort.

\section{MATERIALS AND METHODS PARTICIPANTS}

ELSA-Brasil is a cohort of 15,105 civil servants aged 35-74 years enrolled between August 2008 and December 2010 at six cities (Belo Horizonte, Porto Alegre, Rio de Janeiro, Salvador, Sao Paulo, and Vitoria) designed to investigate the relationship between cardiovascular diseases and diabetes, their social determinants, and risk factors. The study design and sampling procedures of ELSABrasil have been reported previously $(21,22)$. A total of 14,994 participants are reported here after dropping a relatively small number of cases $(n=111)$ with missing data on variables that were included in analyses.

\section{ETHICS STATEMENT}

The ethics committees of the participating universities as well as the National Research Ethics Committee approved the research protocol. All participants provided written informed consent after a complete description of the study.

\section{PSYCHIATRIC EVALUATION}

Mental disorders were determined by trained interviewers using the Portuguese version (23) of the Clinical Interview ScheduleRevised (CIS-R) (24). This is a structured interview used for diagnosis of common, non-psychotic psychiatric conditions in the community. The complete CIS-R version was applied, severity scores were obtained, and common mental disorder status (CIS-R scores $\geq 12$ ), determined. Antidepressant medications [Anatomical Therapeutic Chemical (ATC) Classification code: N06A] included the selective serotonin reuptake inhibitors (SSRI, ATC code: N06AB), the serotonin and noradrenaline reuptake inhibitors (SNRIs, ATC codes: N06AX16/N06AX23/N06AX21), the TCA (ATC code: N06AA), and other antidepressants (N06AX22, N06AX12, N06AA21, N06AX05, N06AX11). Individuals taking at least one antidepressant medicine continuously in the past 2 weeks were classified as users.

\section{CORONARY HEART DISEASE ASSESSMENT}

Coronary heart disease (CHD) included participants with stable angina pectoris, myocardial infarction, and coronary revascularization determined through questionnaire- and intensive interview-based assessment focusing on medical history. All prior $\mathrm{CHD}$ were self-referred by the patients during the structured interview. For the current analysis, prevalent $\mathrm{CHD}$ was defined as a prior history of a physician diagnosed myocardial infarction, a prior percutaneous coronary intervention including balloon angioplasty with or without stent placement, a prior surgical revascularization consisting of either arterial or venous grafts and the history of stable angina as defined by a physician taking care of the participant prior to the inclusion in the ELSA study. The outcome of coronary revascularization was defined as either a percutaneous coronary intervention or a surgical revascularization as previously described.

\section{STATISTICAL ANALYSIS}

Statistical analysis was conducted using IBM SPSS Statistics Version 21. Participant characteristics were examined using independent samples $t$-tests and one-way analyses of variance (ANOVA) for contrasts involving continuous dependent measures, and $\chi^{2}$ statistics for categorical variables. Degrees of freedom were corrected when Levene's Test for Equality of Variances was violated. Tukey's HSD is reported to correct for multiple comparisons and aid interpretation of ANOVA's, while standardized residuals $(z$ scores) were used to help interpret chi-square tests on larger contingency tables [as per Ref. (25)].

A series of univariate and multivariate, binary, logistic regression analyses were then used to estimate the odds ratios and $95 \%$ confidence intervals for the association between antidepressant use as the independent variable (IV) and prevalent CHD (no, yes) as the dependent variable (DV), before and after adjustment for covariates. Unadjusted (univariate) and adjusted (multivariate) analyses were also conducted on specific classes of antidepressants (IV) including the SSRIs, the SNRIs, tricyclic medications and others, and prevalent CHD (no, yes) (DV). Unadjusted univariate, binary, logistic regression analyses (model 1) were conducted on antidepressant use (no versus yes), as well as classes of antidepressants, with no other predictors. Adjusted multivariate analyses (model 2) involved binary logistic regression analysis in which covariates were entered into the first block using the enter method, and antidepressant use was entered into the second (final) block, a technique known as sequential logistic regression analysis. Covariates included age, sex, education (less than high-school, high-school, university), smoking status (never, past/current), body mass index (BMI; weight in kilograms divided by height in meters squared), hypertension (systolic blood pressure $\geq 140 \mathrm{~mm}$ $\mathrm{Hg}$, or diastolic blood pressure $\geq 90 \mathrm{~mm} \mathrm{Hg}$, or use of antihypertensive medications), diabetes mellitus (DM) (self-reported or fasting blood glucose $\geq 126 \mathrm{mg} / \mathrm{dL}, 2$-h oral glucose tolerance 
test $\geq 200 \mathrm{mg} / \mathrm{dL}$, or glycated hemoglobin $\geq 6.5 \%$ ), and severity of mood and anxiety disorders. Sequential, logistic regression analysis is a common approach that allows for the independent contribution of antidepressant use over and above covariates to be determined (26). Statistics from multivariate analyses are reported for the overall model and block (after adjusting for covariates). The block statistic indicates whether or not the IV of interest (antidepressant use/class) is significantly associated with the dependent measure, CHD. Sensitivity analyses were conducted for specific CHD events to determine the consistency of associations across distinct categories of CHD. Sensitivity analyses involved sequential, binary logistic regression analysis in which covariates were entered into block 1 using the enter method, followed by antidepressant use in block 2 (as per model 2).

\section{RESULTS}

\section{PARTICIPANT CHARACTERISTICS}

Table 1 summarizes participant characteristics by CHD status, while Table 2 presents participant characteristics according to antidepressant use. Prevalent CHD was characterized by older age, more men, less education, more smokers, higher BMI, more individuals with DM, hypertension and common mental disorder, higher CIS-R score, and antidepressant use. Antidepressant use was characterized by older age, more women, more education, more smokers, more individuals with CHD and common mental disorder, and higher CIS-R score. Table 3 provides a more detailed breakdown of participant characteristics by antidepressant class. Notably, TCA use is characterized by more women, fewer individuals with college-level education and more with CHD and common mental disorder, and a higher CIS-R score.

ASSOCIATION BETWEEN ANTIDEPRESSANT USE AND PREVALENT CHD Table 4 describes results of analyses assessing the association of antidepressant medications with prevalent CHD. Model 1 relates to the results of unadjusted analyses for antidepressant use [model $\chi^{2}(1)=7.12, p=0.008$ ] and antidepressant class [model $\chi^{2}(4)=14.03, p=0.007$ ], while model 2 relates to results adjusted for covariates [antidepressant use,

Table 1 | Participant characteristics by CHD status $(N=14,994)$.

\begin{tabular}{|c|c|c|c|}
\hline Characteristics & No CHD ( $n=14,284,95 \%)$ & CHD $(n=710,5 \%)$ & Statistic \\
\hline Age, mean (SD) & $51.75(8.97)$ & $58.66(8.74)$ & $t(14,992)=20.07, p<0.001$ \\
\hline Women (\%) & 54.8 & 45.5 & $x^{2}(1)=23.45, p<0.001$ \\
\hline Education (\%) & & & $\chi^{2}(2)=85.16, p<0.001$ \\
\hline Less than high-school & 12.1 & $23.7^{*}$ & \\
\hline High-school & 34.8 & 33.8 & \\
\hline College & 53.1 & $42.5^{*}$ & \\
\hline Smoker (past or current) (\%) & 42.5 & 56.1 & $\chi^{2}(1)=50.77, p<0.001$ \\
\hline Body mass index $\left(\mathrm{kg} / \mathrm{m}^{2}\right)$, mean (SD) & $26.95(4.74)$ & $28.37(4.80)$ & $t(14,992)=7.76, p<0.001$ \\
\hline Diabetes mellitus (yes) (\%) & 18.7 & 37.9 & $\chi^{2}(1)=157.21, p<0.001$ \\
\hline Hypertension (yes) (\%) & 34.0 & 70.0 & $x^{2}(1)=382.49, p<0.001$ \\
\hline Common mental disorder (yes) (\%) & 26.2 & 35.5 & $x^{2}(1)=29.86, p<0.001$ \\
\hline CIS-R Score, mean (SD) & $8.08(7.86)$ & $10.34(9.61)$ & $t(756.82)=6.18, p<0.001$ \\
\hline Antidepressant use (yes) (\%) & 6.0 & 8.6 & $\chi^{2}(1)=7.91, p=0.005$ \\
\hline
\end{tabular}

CIS-R, Clinical Interview Schedule-Revised. ${ }^{*}$ Refers to categories with standardized residuals (z-scores) lying outside \pm 1.96 reflecting a significance value of $p<0.05$.

Table 2 | Participant characteristics by antidepressant use $(N=14,994)$.

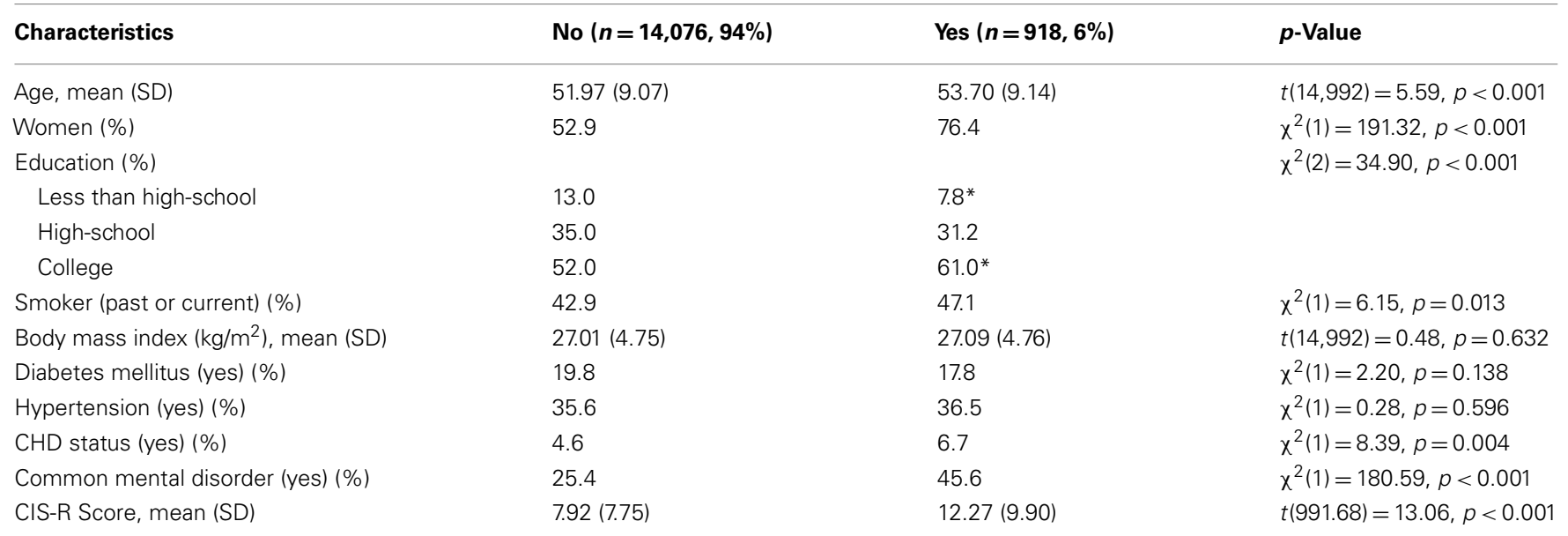

CIS-R, Clinical Interview Schedule-Revised. *Refers to categories with standardized residuals (z-scores) lying outside \pm 1.96 reflecting a significance value of $p<0.05$. 
Table 3 | Participant characteristics by antidepressant grouping $(N=14,994)$

\begin{tabular}{|c|c|c|c|c|c|c|}
\hline Characteristics & $\begin{array}{l}\text { CTL } \\
(n=14,076)\end{array}$ & $\begin{array}{l}\text { SSRI } \\
(n=567)\end{array}$ & $\begin{array}{l}\text { SNRI } \\
(n=100)\end{array}$ & $\begin{array}{l}\text { TCA } \\
(n=156)\end{array}$ & $\begin{array}{l}\text { Other } \\
(n=95)\end{array}$ & $p$-Value \\
\hline Age, mean (SD) & $51.97(9.07)$ & $53.70 *(9.36)$ & $55.48^{*}(8.60)$ & $53.42(8.45)$ & $52.26(9.33)$ & $F(4,14,993)=9.41, p<0.001$ \\
\hline Women, \% & $52.9^{*}$ & $77.8^{*}$ & $81.0^{*}$ & $75.0^{*}$ & 65.3 & $\chi^{2}(4)=197.48, p<0.001$ \\
\hline Education (\%) & & & & & & $\chi^{2}(8)=80.32, p<0.001$ \\
\hline Less than high-school & 13.0 & $6.7^{*}$ & $4.0^{*}$ & 15.4 & 6.3 & \\
\hline High-school & 35.0 & $28.6^{*}$ & $23.0^{*}$ & $47.4^{*}$ & 28.4 & \\
\hline College & 52.0 & $64.7^{*}$ & $73.0^{*}$ & $37.2^{*}$ & 65.3 & \\
\hline Smoker (past or current) (\%) & 42.9 & 47.1 & 40.0 & 47.4 & 53.7 & $\chi^{2}(4)=9.89, p=0.042$ \\
\hline BMI $\left(\mathrm{kg} / \mathrm{m}^{2}\right)$, mean (SD) & $27.01(4.75)$ & $27.12(4.89)$ & $27.68(4.62)$ & $26.83(4.06)$ & $26.69(5.21)$ & $F(4,14,993)=0.731, p=0.571$ \\
\hline Hypertension (yes)\% & 35.6 & 34.9 & 45.0 & 38.5 & 33.7 & $\chi^{2}(4)=4.64, p=0.33$ \\
\hline Diabetes (yes) \% & 19.8 & 17.3 & 18.0 & 20.5 & 15.8 & $\chi^{2}(4)=3.27, p=0.51$ \\
\hline CHD (yes) (\%) & 4.6 & 6.3 & 3.0 & $10.9 *$ & 5.3 & $\chi^{2}(4)=17.61, p=0.001$ \\
\hline Common mental disorder (yes) (\%) & $25.4^{*}$ & $45.0^{*}$ & $43.0^{*}$ & $46.2^{*}$ & $51.6^{*}$ & $x^{2}(4)=182.81, p<0.001$ \\
\hline CIS-R Score, mean (SD) & $7.92(7.75)$ & $12.17(9.70)^{*}$ & $12.19(10.51)^{*}$ & $12.48(10.24)^{*}$ & $12.55(9.94)^{*}$ & $F(4,14,993)=65.42, p<0.001$ \\
\hline
\end{tabular}

${ }^{*}$ Refers to one-way ANOVA in which each group is compared to controls (Tukey's HSD, $\left.p<0.05\right)$ or standardized residuals (z-scores) from $\chi^{2}$ statistics lying outside \pm 1.96 reflecting a significance value of $p<0.05$.

Table 4 | Unadjusted (model 1) $)^{\mathrm{a}}$ and adjusted (model 2) ${ }^{\mathrm{b}}$ associations between antidepressant use and $\mathrm{CHD}(\mathrm{N}=14,994)$.

\begin{tabular}{|c|c|c|c|c|c|c|c|c|}
\hline Predictor & $N$ & \multicolumn{3}{|c|}{ CHD: model $1^{\mathrm{a}}(n=710)$} & $N$ & \multicolumn{3}{|c|}{ CHD: model $2^{b}(n=710)$} \\
\hline No & 14,076 & & REF & & 14,076 & & REF & \\
\hline Yes & 918 & 1.47 & $1.12-1.93$ & 0.005 & 918 & 1.28 & $0.96-1.71$ & 0.093 \\
\hline \multicolumn{9}{|c|}{ Antidepressant groupings } \\
\hline SSRI & 567 & 1.40 & $0.99-1.98$ & 0.056 & 567 & 1.26 & $0.87-1.81$ & 0.218 \\
\hline SNRI & 100 & 0.64 & $0.20-2.02$ & 0.447 & 100 & 0.47 & $0.15-1.52$ & 0.209 \\
\hline TCA & 156 & 2.53 & $1.52-4.21$ & $<0.001$ & 156 & 2.15 & $1.24-3.71$ & 0.006 \\
\hline Other & 95 & 1.15 & $0.47-2.84$ & 0.763 & 95 & 1.03 & $0.40-2.65$ & 0.949 \\
\hline
\end{tabular}

${ }^{a}$ Model 1 relates to separate unadjusted analyses for any antidepressant use and specific classes of antidepressant including SSRI (selective serotonin reuptake inhibitors), SNRI (serotonin and noradrenaline reuptake inhibitors), TCA (tricyclic antidepressants), and other.

${ }^{b}$ Model 2 relates to analyses adjusted for covariates.

model $\chi^{2}(10)=724.85, p<0.001$; block $\chi^{2}(1)=2.69, p=0.101$; antidepressant class, model $\chi^{2}(10)=732.04, p<0.001$; block $\left.\chi^{2}(4)=9.88, p=0.042\right]$. Antidepressant use was associated with a 1.5-fold increase in the odds of prevalent CHD (95\% CI: 1.121.93) (model 1), although this was reduced to a 1.3-fold increase when adjusting for covariates (95\% CI: 0.96-1.71) (model 2). Sensitivity analysis revealed that use of TCAs $(\mathrm{OR}=2.53,95 \% \mathrm{CI}$ : 1.52-4.21, model 1 ; OR $=2.15,95 \% \mathrm{CI}=1.24-3.71)$ in particular is significantly associated with prevalent CHD.

ASSOCIATION BETWEEN ANTIDEPRESSANT USE AND CHD SUBTYPES Table 5 reports results for the additional specificity analyses on stable angina pectoris [antidepressant use: model $\chi^{2}(10)=223.26, p<0.001$; block $\chi^{2}(1)=0.02, p=0.891$; antidepressant class: model $\chi^{2}(13)=223.26, \quad p<0.001$; block $\chi^{2}(4)=3.02, p=0.555$ ], myocardial infarction [antidepressant use: model $\chi^{2}(10)=426.90, p<0.001 ;$ block $\chi^{2}(1)=0.83$, $p=0.361$; antidepressant class: model $\chi^{2}(13)=437.14, p<0.001$; block $\left.\chi^{2}(4)=11.07, p=0.026\right]$, and coronary revascularization [antidepressant use: model $\chi^{2}(10)=440.68, p<0.001$; block $\chi^{2}(1)=6.02, \quad p=0.014$; antidepressant class: model $\chi^{2}(13)=448.41, p<0.001 ;$ block $\left.\chi^{2}(4)=13.75, p=0.008\right]$. While there were no significant associations observed for stable angina, use of tricyclic medications were associated with a threefold increase in odds for myocardial infarction as well as coronary revascularization. These additional findings indicate that the association between TCA use and prevalent CHD is specific to "hard" CHD events including myocardial infarction and coronary revascularization.

\section{DISCUSSION}

The goal of this study was to determine the associations between use of antidepressant medications and prevalent $\mathrm{CHD}$ in a cohort of civil servants from Brazil. This is an important goal because 
Table 5 | Fully adjusted association between antidepressant use and CHD subtypes $(N=14,994)$.

\begin{tabular}{|c|c|c|c|c|c|c|c|c|c|c|c|c|}
\hline \multirow[t]{2}{*}{ Predictor } & \multirow[t]{2}{*}{$N$} & \multicolumn{3}{|c|}{$\begin{array}{l}\text { Stable angina } \\
(n=312)^{a}\end{array}$} & \multirow[t]{2}{*}{$N$} & \multicolumn{3}{|c|}{$\begin{array}{l}\text { Myocardial infarction } \\
(n=267)\end{array}$} & \multirow[t]{2}{*}{$\boldsymbol{N}$} & \multicolumn{3}{|c|}{$\begin{array}{l}\text { Coronary } \\
\text { revascularization }(n=255)\end{array}$} \\
\hline & & OR & $95 \% \mathrm{Cl}$ & $p$-Value & & OR & $95 \% \mathrm{Cl}$ & $p$-Value & & OR & $95 \% \mathrm{Cl}$ & $p$-Value \\
\hline \multicolumn{13}{|c|}{ Any antidepressant use } \\
\hline No & 13,715 & & & REF & 14,076 & & & REF & 14,076 & & & REF \\
\hline Yes & 881 & 0.85 & $0.54-1.36$ & 0.501 & 918 & 1.25 & $0.78-2.01$ & 0.349 & 918 & 1.79 & $1.15-2.77$ & 0.009 \\
\hline \multicolumn{13}{|c|}{ Antidepressant groupings } \\
\hline None & 13,715 & & & & 14,076 & & & REF & 14,076 & & REF & \\
\hline SSRI & 546 & 1.00 & $0.58-1.71$ & 0.989 & 567 & 1.12 & $0.59-2.10$ & 0.735 & 567 & 1.96 & 1.16-3.34 & 0.013 \\
\hline SNRI & 98 & 0.30 & $0.04-2.16$ & 0.229 & 100 & $\mathrm{n} / \mathrm{a}$ & $\mathrm{n} / \mathrm{a}$ & 0.996 & 100 & 1.15 & $0.27-4.85$ & 0.845 \\
\hline TCA & 143 & 1.01 & $0.37-2.79$ & 0.986 & 156 & 2.96 & $1.41-6.21$ & 0.004 & 156 & 2.92 & $1.28-6.66$ & 0.011 \\
\hline Other & 94 & 1.65 & $0.59-4.64$ & 0.340 & 95 & 0.54 & $0.07-4.03$ & 0.547 & 95 & n/a & $\mathrm{n} / \mathrm{a}$ & 0.996 \\
\hline
\end{tabular}

${ }^{a}$ This model excludes 398 participants with myocardial infarction or coronary revascularization.

Brazil currently faces many socioeconomic inequities, which may impact on antidepressant usage. Major findings indicate that use of TCA is associated with: (1) a twofold increase in the odds for prevalent CHD and (2), a threefold increase in the odds for myocardial infarction and coronary revascularization, after adjustment for covariates. The associated 95\% confidence intervals for TCA use - all of which excluded the null value of 1 - provide sets of likely values for the odds ratio on which for a repeated study would most likely fall (on average, a five-in-six chance) (27). Values close to the sample estimates, however, are $\sim 7$ times more likely to reflect the true population estimate $(\mu)$, than values near the limits of the interval (27). These considerations and the size of the effects obtained, enhance our confidence in the reported findings reported here.

While our study highlights a strong relationship between TCA use and "hard" CHD events, it is important to acknowledge that some participants in our study may have been using low-dose TCAs to treat conditions other than mental disorders, such as chronic/neuropathic pain and sleep issues. Importantly, research has demonstrated a dose-related increase in sudden cardiac death in current users of TCAs from 0.97 for doses lower than $100 \mathrm{mg}$ (amitriptyline or its equivalent) to 2.53 for doses of $300 \mathrm{mg}$ or more, highlighting that doses of $<100 \mathrm{mg}$ does not increase risk (at least for sudden cardiac death). However, current recommendations indicate that TCAs should be avoided completely in cardiac patients (7). In Brazil, access to TCAs is free $(18,19)$, while access to other classes of antidepressants is restricted suggesting socioeconomic reasons that may increase the association between TCA and prevalent CHD. It is notable that elderly Brazilian patients with psychiatric disorders are 5.3 times more likely to be using inappropriate medications (28). We suggest that these previous findings (28) may help to understand the findings that we report here, which may indicate problems associated with ongoing health care of cardiac patients in the Brazilian population.

It is important to acknowledge the cross-sectional design as an important limitation of the present study. This limitation precludes any conclusions over the causal relationship between TCA use and CHD. For instance, it is equally possible that TCA use preceded the development of $\mathrm{CHD}$ consistent with research that suggests TCAs lead to cardiovascular events [e.g., Ref. (17)] (i.e., a biological explanation) beyond that explained by psychiatric illness, or that TCAs were prescribed after CHD was diagnosed consistent with research that suggests patients may be inappropriately medicated in Brazil [e.g., Ref. (28)] (i.e., a sociodemographic explanation). However, regardless of the causal direction of the relationship between TCA use and $\mathrm{CHD}$, our findings still have important implications for the treatment of cardiac patients in Brazil. It is notable here that research from the Netherlands (5), a high-income country, did not observe a significant association between use of TCAs and CHD. The authors noted that while the adverse cardiovascular effects of TCAs are well known, a null finding might reflect the contraindication of TCA use in heart patients. We suggest here that socioeconomic inequities in Brazil may over-ride recommendations to avoid these medications in cardiac patients as patients have easier and free access to this class of antidepressant medications through free public health care.

Longitudinal research (8) from the Netherlands Study of Depression and Anxiety $(N=2,114)$ indicates that all classes of antidepressants may have adverse effects on heart function, determined by reductions in heart rate variability, a psychophysiological predictor of future cardiovascular mortality [see in Ref. (29) for review]. Adverse effects were greatest for the TCAs, followed by the SNRIs, and then the SSRIs, relative to no antidepressant use (8) [see also in Ref. (30)]. This study also reported that these effects disappear when antidepressants are discontinued. However, the adverse effects reported for the SSRI class were small, which may, in part, explain the contradictory findings reported previously for the association between SSRIs and CHD $(9,17)$. SSRI antidepressants are generally considered to have a more favorable cardiovascular profile than the TCA (and the serotonin and noradrenaline reuptake inhibitors, or SNRIs). The SSRIs may exert cardiovascular benefits through direct action on the biological substrates of the stress response (31), including a blunting of blood pressure, myocardial responses, and cortisol reactivity under stress. The SSRIs also have antiplatelet properties, which will reduce the risk for thrombus formation $(2,3)$. While we did not observe a relationship between SSRIs and prevalent CHD, we did observe 
a twofold increase association for SSRIs and coronary revascularization. A possible explanation for the null association between SSRIs and myocardial infarction is the restricted access to antidepressants from the SSRI class of antidepressants, resulting perhaps from the socioeconomic inequities of Brazilian mental health care $(28,32,33)$ and high cost of these newer medications.

In conclusion, the present study provides important new information on the association of antidepressant use and prevalent CHD in Brazil. While a limitation of our study is its cross-sectional design, this limitation does not undermine the importance of our findings, as TCA use in patients with CHD increases risk of future morbidity and mortality. While it is possible that some of our participants were on low-dose TCAs for conditions other than depression and anxiety, recommendations from high-income countries suggest that these medications should be avoided in cardiac patients. Our study is characterized by a number of strengths including a focus on a relatively large and well-characterized sample of the Brazilian population, application of a structured clinical interview to determine psychiatric diagnosis and disorder severity, and adjustment for a host of covariates known to contribute to metabolic and cardiovascular risk. Our findings indicate a strong relationship between TCA use and prevalent CHD. We will further examine the impact of the different antidepressant classes in a longitudinal follow-up study of the ELSA-Brasil cohort once data collection is complete.

\section{AUTHOR CONTRIBUTIONS}

Andrew H. Kemp conducted the literature search, identified the research questions, and clarified the hypotheses. He analyzed the data, interpreted the results, and wrote the paper. Maria A. Nunes adapted the Clinical Interview Schedule for use in our project and was responsible for the psychiatric evaluations of participants recruited in ELSA-Brasil. Isabela M. Bensen or and Paulo A. Lotufo have been involved in the ELSA-Brasil project since its inception, and secured the funding to initiate and conduct the project. They were involved in all aspects of the present study including research design, data collection, analysis, and interpretation of results. All authors reviewed and approved the manuscript for publication.

\section{ACKNOWLEDGMENTS}

Andrew H. Kemp is supported by an International Research Professorship from the Universidade de São Paulo, Brazil. Isabela M. Bensen or and Paulo A. Lotufo are recipients of an award for established researchers from CNPq. Andre R. Brunoni is a recipient of a young investigator award from FAPESP, São Paulo, Brazil. The ELSA-Brasil baseline study was supported by the Brazilian Ministry of Health (Science and Technology Department) and the Brazilian Ministry of Science and Technology (Financiadora de Estudos e Projetos and CNPq National Research Council) (grants 01060010.00 RS, 01060212.00 BA, 01060300.00 ES, 0106 0278.00 MG, $01060115.00 \mathrm{SP}, 01060071.00 \mathrm{RJ})$. The funders had no role in study design, data collection and analysis, decision to publish, or preparation of the manuscript. The authors would also like to acknowledge the participation of the 15,105 individuals recruited for this study without which this study and those based on the ELSA-Brasil cohort would not have been possible.

\section{REFERENCES}

1. Murray C, Vos T, Lozano R, Naghavi M, Flaxman AD. Disability-adjusted life years (DALYs) for 291 diseases and injuries in 21 regions, 1990-2010: a systematic analysis for the Global Burden of Disease Study 2010. Lancet (2013) 380:2197-223. doi:10.1016/S0140-6736(12)61689-4

2. Nemeroff C, Goldschmidt-Clermont PJ. Heartache and heartbreak - the link between depression and cardiovascular disease. Nat Rev Cardiol (2012) 9(9):526-39. doi:10.1038/nrcardio.2012.91

3. Stapelberg NJ, Hamilton-Craig I, Neumann DL, Shum DHK, McConnell H. Mind and heart: heart rate variability in major depressive disorder and coronary heart disease - a review and recommendations. Aust N Z J Psychiatry (2012) 46(10):946-57. doi:10.1177/0004867412444624

4. Lichtman JH, Froelicher ES, Blumenthal JA, Carney RM, Doering LV, FrasureSmith N, et al. Depression as a risk factor for poor prognosis among patients with acute coronary syndrome: systematic review and recommendations: a scientific statement from the American Heart Association. Circulation (2014) 129(12):1350-69. doi:10.1161/CIR.0000000000000019

5. Vogelzangs N, Seldenrijk A, Beekman ATF, van Hout HPJ, de Jonge P, Penninx BWJH. Cardiovascular disease in persons with depressive and anxiety disorders. J Affect Disord (2010) 125(1-3):241-8. doi:10.1016/j.jad.2010.02.112

6. Tully PJ, Cosh SM. Generalized anxiety disorder prevalence and comorbidity with depression in coronary heart disease: a meta-analysis. J Health Psychol (2013) 18:1601-16. doi:10.1177/1359105312467390

7. Colquhoun DM, Bunker SJ, Clarke DM, Glozier N, Hare DL, Hickie IB, et al. Screening, referral and treatment for depression in patients with coronary heart disease. Med J Aust (2013) 198(9):483-4. doi:10.5694/mja13.10153

8. Licht CMM, de Geus EJC, van Dyck R, Penninx BWJH. Longitudinal evidence for unfavorable effects of antidepressants on heart rate variability. Biol Psychiatry (2010) 68(9):861-8. doi:10.1016/j.biopsych.2010.06.032

9. Whang W, Kubzansky LD, Kawachi I, Rexrode KM, Kroenke CH, Glynn RJ, et al. Depression and risk of sudden cardiac death and coronary heart disease in women. J Am Coll Cardiol (2009) 53(11):950-8. doi:10.1016/j.jacc.2008.10.060

10. Kemp AH, Quintana DS, Malhi GS. Effects of serotonin reuptake inhibitors on heart rate variability: methodological issues, medical comorbidity, and clinical relevance. Biol Psychiatry (2011) 69(8):e25-6. doi:10.1016/j.biopsych.2010. 10.035

11. Kemp AH. Depression, antidepressant treatment and the cardiovascular system. Acta Neuropsychiatr (2011) 23(2):82-3. doi:10.1111/j.1601-5215.2011.00535.x

12. Pizzi C, Rutjes AWS, Costa GM, Fontana F, Mezzetti A, Manzoli L. Meta-analysis of selective serotonin reuptake inhibitors in patients with depression and coronary heart disease. Am J Cardiol (2011) 107(7):972-9. doi:10.1016/j.amjcard. 2010.11.017

13. Glassman AH. The safety of tricyclic antidepressants in cardiac patients riskbenefit reconsidered. JAMA (1993) 269(20):2673-5. doi:10.1001/jama.269.20. 2673

14. Richelson E. Synaptic effects of antidepressants. J Clin Psychopharmacol (1996) 16(3):1S-7S. doi:10.1097/00004714-199606002-00002

15. Coupland N, Wilson S, Nutt D. Antidepressant drugs and the cardiovascular system: a comparison of tricylics and selective serotonin reuptake inhibitors and their relevance for the treatment of psychiatric patients with cardiovascular problems. J Psychopharmacol (1997) 11(1):83-92. doi:10.1177/ 026988119701100118

16. Tata LJ, West J, Smith C, Farrington P, Card T, Smeeth L, et al. General population based study of the impact of tricyclic and selective serotonin reuptake inhibitor antidepressants on the risk of acute myocardial infarction. Heart (2005) 91(4):465-71. doi:10.1136/hrt.2004.037457

17. Hamer M, David Batty G, Seldenrijk A, Kivimaki M. Antidepressant medication use and future risk of cardiovascular disease: the Scottish health survey. Eur Heart J (2011) 32(4):437-42. doi:10.1093/eurheartj/ehq438

18. Brunoni AR, Nunes MA, Figueiredo R, Barreto SM, da Fonseca M, de JM, et al. Patterns of benzodiazepine and antidepressant use among middle-aged adults. the Brazilian longitudinal study of adult health (ELSA-Brasil). J Affect Disord (2013) 151(1):71-7. doi:10.1016/j.jad.2013.05.054

19. Burr RL. Interpretation of normalized spectral heart rate variability indices in sleep research: a critical review. Sleep (2007) 30(7):913-9.

20. Moore RA, Derry S, Aldington D, Cole P, Wiffen PJ. Amitriptyline for neuropathic pain and fibromyalgia in adults. Cochrane Database Syst Rev (2012) 12:CD008242. doi:10.1002/14651858.CD008242.pub2 
21. Aquino EML, Barreto SM, Benseñor IM, Carvalho MS, Chor D, Duncan BB, et al. Brazilian longitudinal study of adult health (ELSA-Brasil): objectives and design. Am J Epidemiol (2012) 175(4):315-24. doi:10.1093/aje/kwr294

22. Schmidt MI, Duncan BB, Mill JG, Lotufo PA, Chor D, Barreto SM, et al. Cohort profile: longitudinal study of adult health (ELSA-Brasil). Int J Epidemiol (2014). doi:10.1093/ije/dyu027

23. Nunes MA, de Mello Alves MG, Chor D, Schmidt MI, Duncan BB. Adaptação transcultural do CIS-R (clinical interview schedule-revised version) para o português no Estudo Longitudinal De Saúde Do Adulto (ELSA). Revista HCPA (2012) 31(4):487-90.

24. Lewis G, Pelosi AJ, Araya R, Dunn G. Measuring psychiatric disorder in the community: a standardized assessment for use by lay interviewers. Psychol Med (1992) 22(2):465-86. doi:10.1017/S0033291700030415

25. Field A. Discovering Statistics using IBM SPSS Statistics. 4 ed. London: SAGE (2013). 1 p.

26. Tabachnick BG, Fidell LS. Using Multivariate Statistics. 6 ed. Boston: Pearson (2012).

27. Cumming G. The new statistics: why and how. Psychol Sci (2014) 25(1):7-29. doi:10.1177/0956797613504966

28. de Lima TSJV, Garbin CAAS, Garbin ANJS, Sumida DRH, Saliba O. Potentially inappropriate medications used by the elderly: prevalence and risk factors in Brazilian care homes. BMC Geriatr (2013) 13(1):52. doi:10.1186/1471-231813-52

29. Kemp AH, Quintana DS. The relationship between mental and physical health: insights from the study of heart rate variability. Int J Psychophysiol (2013) 89(3):288-96. doi:10.1016/j.ijpsycho.2013.06.018

30. Kemp AH, Brunoni AR, Santos IS, Nunes MA, Dantas EM, Carvalho de Figueiredo R, et al. Effects of depression, anxiety, comorbidity, and antidepressants on resting-state heart rate and its variability: an ELSA-Brasil cohort baseline study. Am J Psychiatr (2014) 171:1328-34. doi:10.1176/appi.ajp.2014. 13121605
31. Straneva-Meuse PA, Light KC, Allen MT, Golding M, Girdler SS. Bupropion and paroxetine differentially influence cardiovascular and neuroendocrine responses to stress in depressed patients. J Affect Disord (2004) 79(1-3):51-61. doi:10.1016/S0165-0327(02)00352-X

32. Bertoldi AADM, Helfer AP, Camargo AL, Tavares NMUL, Kanavos P. Is the Brazilian pharmaceutical policy ensuring population access to essential medicines? Global Health (2012) 8(1):1-1. doi:10.1186/1744-8603-8-6

33. Cruz L, Lima AFDS, Graeff-Martins A, Maia CRM, Ziegelmann P, Miguel S, et al. Review article mental health economics: insights from Brazil. J Ment Health (2013) 22(2):111-21. doi:10.3109/09638237.2012.759193

Conflict of Interest Statement: The authors declare that the research was conducted in the absence of any commercial or financial relationships that could be construed as a potential conflict of interest.

Received: 16 October 2014; accepted: 07 January 2015; published online: 22 January 2015.

Citation: Kemp AH, Brunoni AR, Bittencourt MS, Nunes MA, Benseñor IM and Lotufo PA (2015) The association between antidepressant medications and coronary heart disease in Brazil: a cross-sectional analysis on the Brazilian longitudinal study of adult health (ELSA-Brazil). Front. Public Health 3:9. doi: 10.3389/fpubh.2015.00009 This article was submitted to Epidemiology, a section of the journal Frontiers in Public Health.

Copyright (C) 2015 Kemp, Brunoni, Bittencourt, Nunes, Benseñor and Lotufo. This is an open-access article distributed under the terms of the Creative Commons Attribution License (CC BY). The use, distribution or reproduction in other forums is permitted, provided the original author(s) or licensor are credited and that the original publication in this journal is cited, in accordance with accepted academic practice. No use, distribution or reproduction is permitted which does not comply with these terms. 